Janosch Dlouhy, Miguel Ricalde, Bernardo Cossio and Carlos Januncio. (2018). "Large scale project using takt planning and takt control. - Creating and sustaining multitasking flow." In: Proc. 26th Annual Conference of the International. Group for Lean Construction (IGLC), González, V.A. (ed.), Chennai, India, pp. 1334-1343. DOI: doi.org/10.24928/2018/0503. Available at: www.iglc.net

\title{
LARGE SCALE PROJECT USING TAKT PLANNING AND TAKT CONTROL-CREATING AND SUSTAINING MULTITASKING FLOW
}

\author{
Janosch Dlouhy $^{1}$, Miguel Ricalde ${ }^{2}$, Bernardo Cossio ${ }^{3}$, Carlos Januncio ${ }^{4}$
}

\begin{abstract}
Takt planning and Takt control (TPTC) is a production system approach that is most commonly used in individual construction projects. The approach has not yet been implemented systematically in a large-scale project, like a Greenfield automotive plant (complete new plant from scratch) with all facilities. Furthermore, its use has not been documented in construction in Mexico. Most projects describing TPTC in research are single contractor projects, implemented by a single construction company. This paper describes a real project with over 15 different facilities using Takt planning and Takt control (TPTC), in a large scale green field automotive plant with 5 main general contractors collaborating together with the client. It shows the demands and the effects of large scale projects using the method of TPTC within a Lean philosophy and describes the system that was designed and implemented. As the main contribution from this paper, a system and its results for creating a Lean culture, collaboration, transparency, planning and overall project control within a multitasking flow is described and validated.
\end{abstract}

\section{KEYWORDS}

Lean construction, Takt planning, Takt control, Collaboration, large-scale projects.

\section{INTRODUCTION}

The approach of Takt is defined in different IGLC paper before (Horman et al., 2003) and (Frandson et al., 2013). All case studies known by the authors are describing single projects using Takt.

The new construction of a complete, green field plant requires a huge effort in project management and administration. Facilitating information flow to all practitioners, controlling construction processes, planning and sustaining site logistics, while focusing on the client's values(and changes to their demands), as well as coordinating all buildings from different construction companies, while ensuring delivery in time by for connection

\footnotetext{
Process Specialist, Construction Department, BMW AG, Munich, Germany, Janosch.dlouhy@bmw.de Lean Construction Specialist, AECOM, Mexico, San Luis Potosi, miguel.ricalde@gmail.com

Lean Consultant, ITN Mexico, Mexico City, bcossio@itnmexico.com

Lean Construction Specialist, AECOM, Brasil, carlosjanuncio@gmail.com
} 
to infrastructure are only some of the many requirements for a project's management system. As a response to these demands and requests from the client, a Takt planning and Takt controlling approach from Germany was adapted for use in a real large-scale project in Mexico (Binninger et al., 2017a), thereby enabling complete transparency and collaboration, with the possibility of detailing everything, everywhere. This paper shows the implementation, operation and validation of that real-world case study.

\section{PROJECT DESCRIPTION}

The plant was built in a green field, where all services and infrastructure had to be built entirely new. The project required several bid-packages (groups of buildings) to be tendered. An overview of the project is given in figure 1, with the main buildings and the key highlights on the right.

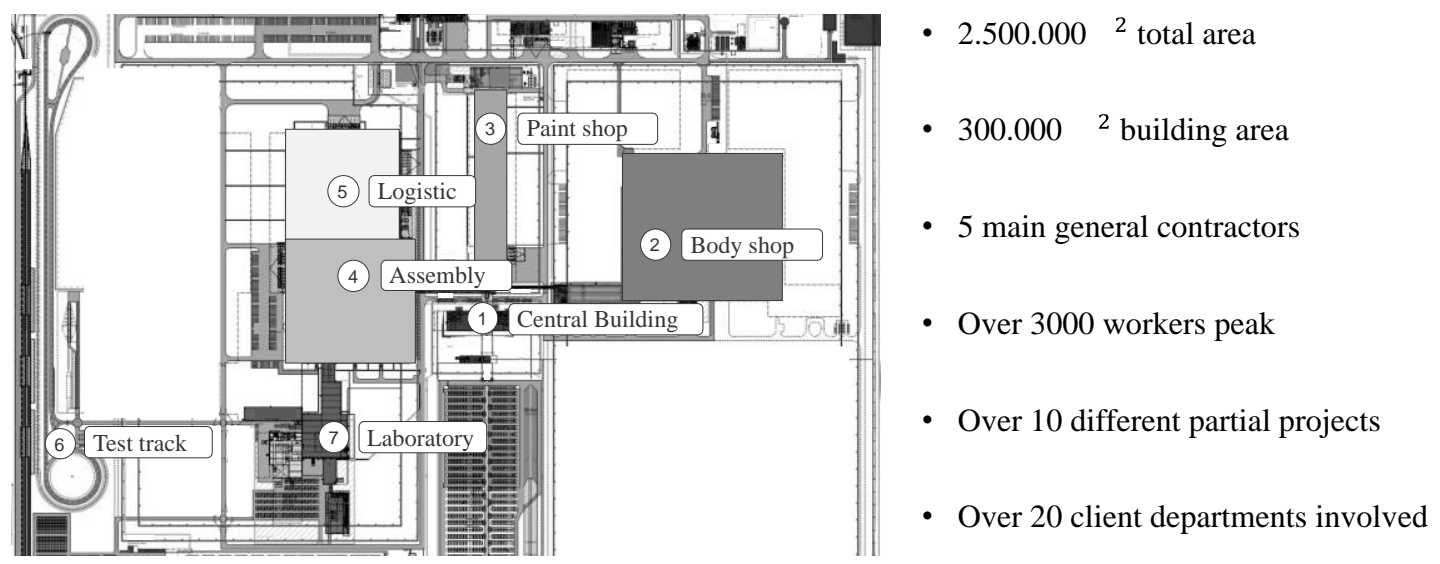

Figure 1: Overview Car Manufacture Plant Mexico

\section{IMPLEMENTATION}

\section{SYSTEMATIC APPROACH}

The client's organization already possessed TPTC experience in more than 20 single projects in different cultures, before the start of the green field plant in Mexico. As a key enabler to meet the client's expectations (in terms of the quality of the product), as well as the process in construction (which was high for Mexican standard) and to integrate the client ( by managing the multi-project's transparency of flow), the 3 Level Model (Dlouhy et al., 2016) was used. The Takt planning approach sought to help align the expectations with the execution of construction, synchronize and harmonize all different construction projects. The aim was to enable the entire project management of all stakeholders and external participants to pull requested information, as shown in Figure 2. 


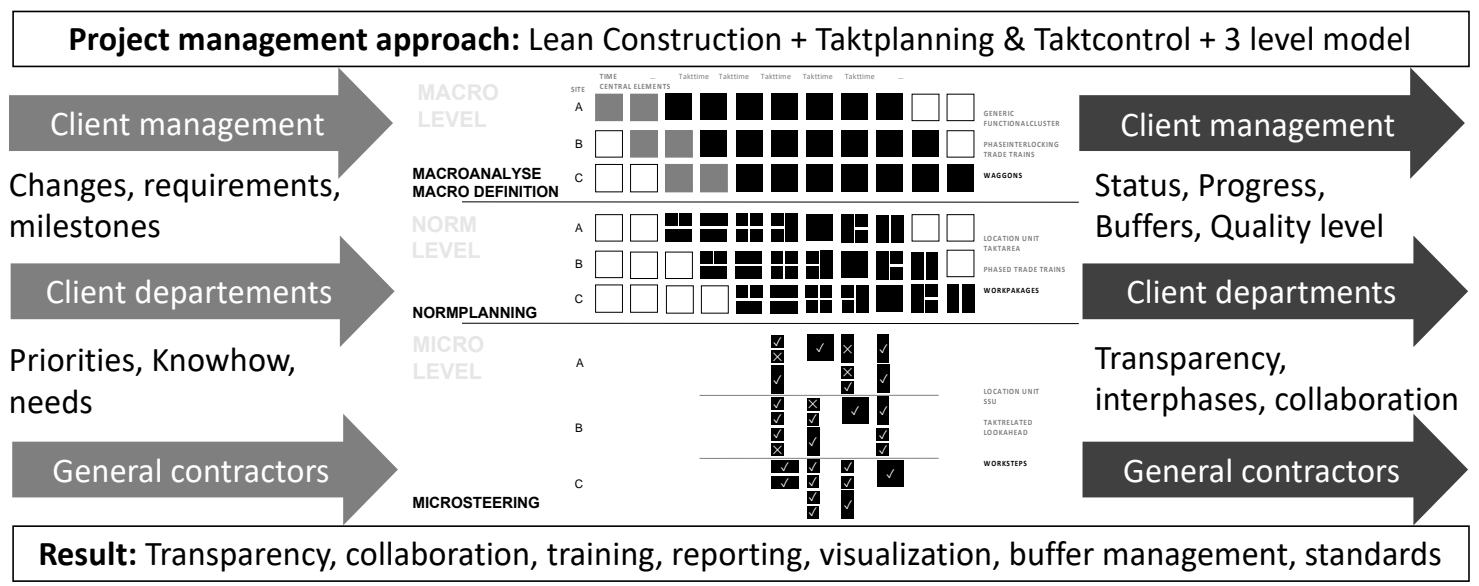

Figure 2: Organizing a value related large-scale project management

\section{CLIENT INTERVIEW}

Understanding the client's requirements and value perception was fundamental to define the priorities for construction. This knowledge is used to align the project's phases, to identify time buffers and optimize the construction process (Dlouhy et al., 2016, p. 18f.). This was accomplished by including the production line planners in the workshops. At this time both project team and client could identify other needs that had not been previously identified. Decisions could be made in terms of what kind of resources the project requires, where they should be and by when they should be accomplished.

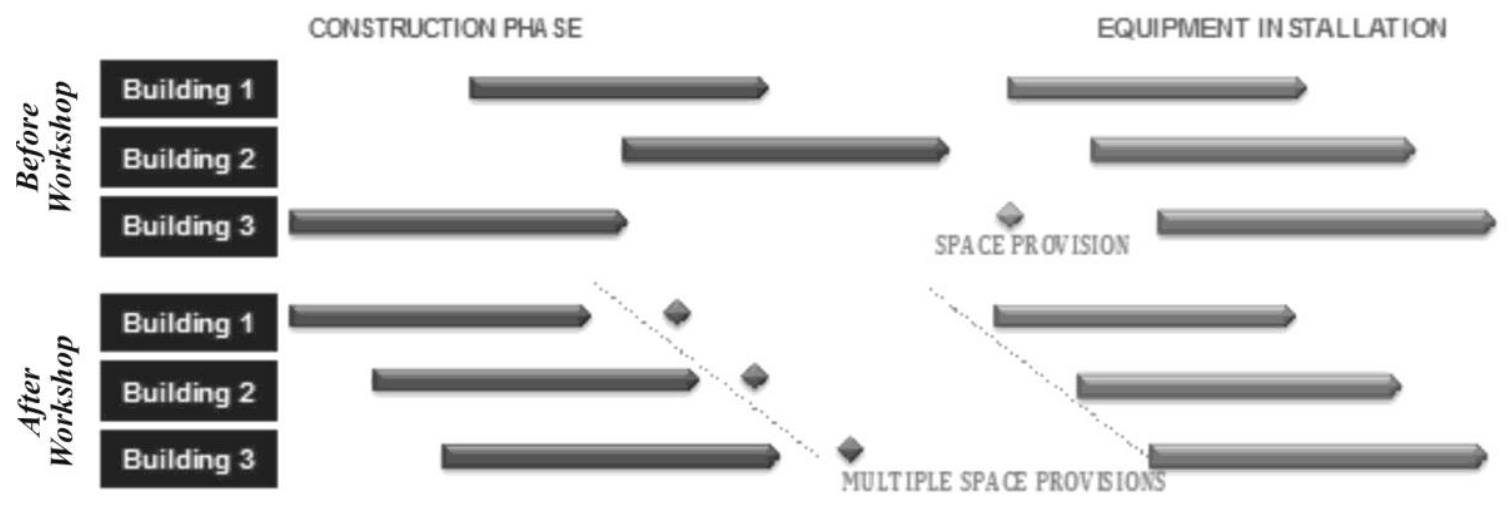

Figure 3: Re-phasing the project based on realigned priorities

\section{IMPLEMENTATION STRATEGY}

The implementation of a multi-project TPTC was planned from the beginning of the project and based on previous smaller TPTC deployments like the example of a fire station (Binninger et al., 2017a, p. 609ff.) of a smaller plant in Brazil (Dlouhy et al., 2016, p. 18ff.).It had been determined that a large-scale project would require establishing a common set of tools, understanding, and language between the various stakeholders 
involved (clients, project managers, general contractors and subcontractors) in order to facilitate a collaborative environment across all levels of the organizations.

During the bid process, each participating general contractor was consulted regarding their experience with the TPTC method and Lean Construction. 95\% stated having had little or no experience, thus confirming the need to establish a formal strategy. The client's previous experiences in similar scenarios set the guideline to establish Lean as a contractual requirement. Furthermore, clear advice was given to the selected GCs to hire local Lean Construction consultants to accelerate the learning curve and sustain the implementation of Lean within their companies.

A framework was created to introduce Lean and TPTC to each participant, clarifying in each step the requirements and workflow needed in a TPTC and Lean environment (see table 1).

Table. 1: Client's framework for Lean as contractual requirement.

\begin{tabular}{|c|c|c|}
\hline Phase & Participants & Action \\
\hline Set up project & Client members & $\begin{array}{l}\text { Training and developing implementing } \\
\text { strategy }\end{array}$ \\
\hline $\begin{array}{l}\text { Hiring construction } \\
\text { management }\end{array}$ & $\begin{array}{l}\text { Client/ project } \\
\text { management }\end{array}$ & $\begin{array}{l}\text { Establishing Lean construction in the pm } \\
\text { contracts, establishing a Lean Team }\end{array}$ \\
\hline Pre - Bid Meeting & Client/ GC Directors & Introduction to Lean Thinking \\
\hline Clarification Meeting & Client/ GC Directors & Answer/ questions with clarification \\
\hline Contract & Client/ GC & $\begin{array}{l}\text { Lean as a requirement in the contract, with } \\
\text { description of the method TPTC }\end{array}$ \\
\hline Kickoff Meeting & Client/ GC Team & $\begin{array}{l}\text { Request correct information for workshops } \\
\text { and implementation }\end{array}$ \\
\hline
\end{tabular}

\section{QUALIFICATION}

The professional client has been using a training system with different stages and levels, to implement Lean in the client organization and in their projects (Dlouhy and Wagner, 2018, p. 112 ff.) using a Takt simulation (cf. Binninger et al., 2017b). In this large-scale project, the training was extended to the systematic needs of a multi-contractor and multibuilding project.

The responsible project managers were trained inside the client organization before the start of the construction phase. First elements of Lean were implemented during the design phase.

\section{OPERATING SYSTEM}

The operating system of the TPTC and Lean methodologies in this project was based on 3 main subsystems: creating and sustaining a Lean culture, continuous planning, and multilevel communication. 


\section{CREATING AND SUSTAINING A LEAN CULTURE}

Following the implementation strategy mentioned earlier, a diverse Lean training program was developed to focus on individual target groups (See figure 4). Levels 1 and 2 consisted of intensive workshops with durations of 2-3 days to immerse GC's owners, directors and project managers in TPTC and Lean thinking, gaining as a result their buyin to the philosophy. Goals for levels 3 and 4 were to sustain the level of knowledge and adherence to the set standards, as well as to improve the implemented TPTC and other Lean tools. Since these levels (3 and 4) were targeting field engineers and construction workers, shorter interval training sessions were deemed more suitable to avoid disrupting the workflow.

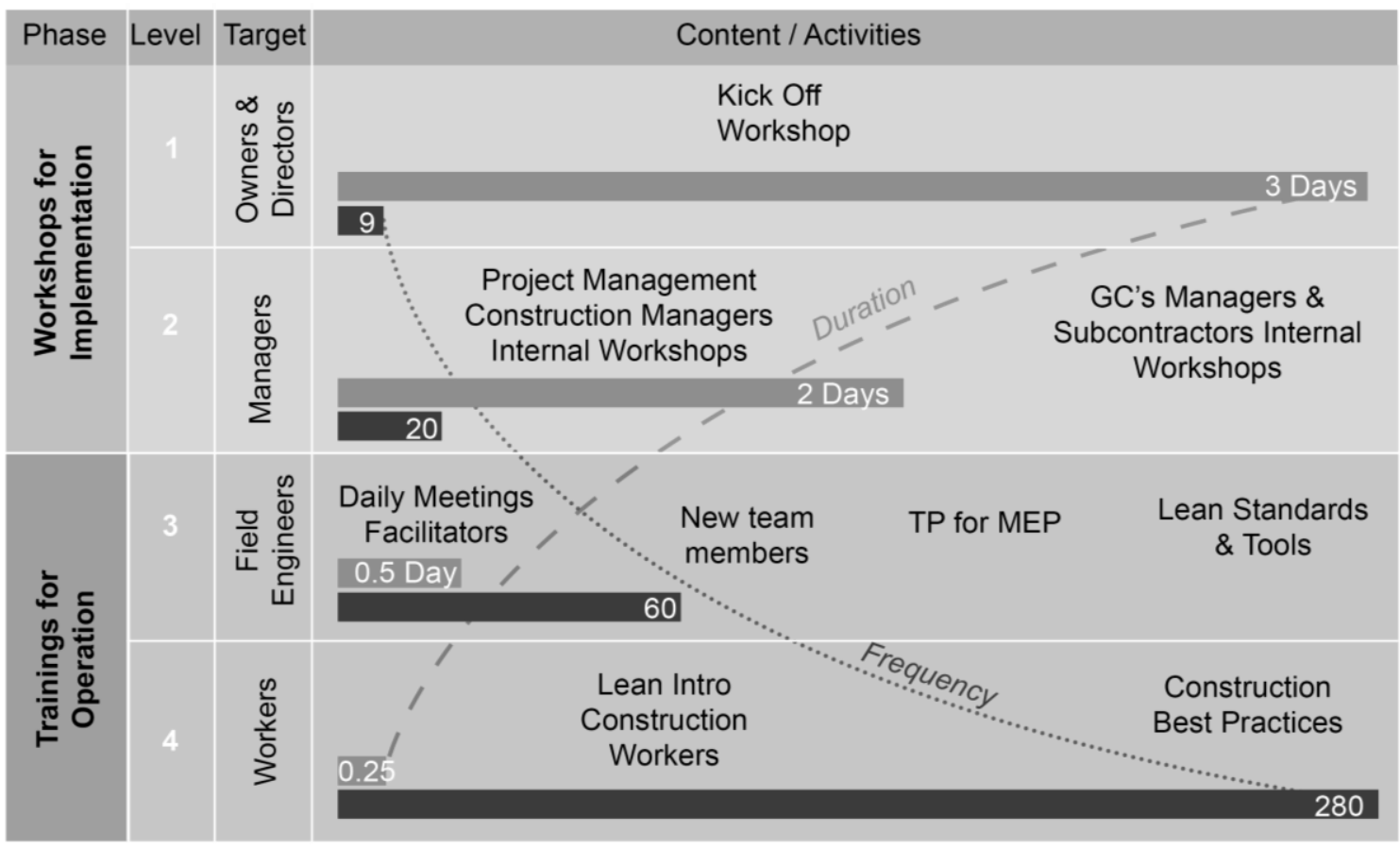

Figure 4: Levels of Training to establish a Lean project culture

\section{CONTINUOUS PLANNING}

The aim of planning a large-scale project with diverse contractors and buildings at different stages is to optimize the workflow; not only the individual demands, but also to the overall demands of the project. This includes being able to reduce delays and balance workloads to maintain and promote the entire project progress. The planning workflow consisted of a 4-tier structure behaving transparently in a bottom-up and top-down information flow, involving weekly revisions on the Norm Level and daily adaptation on the Micro Level, informing each other of improvement opportunities and requirements (See figure 5). 


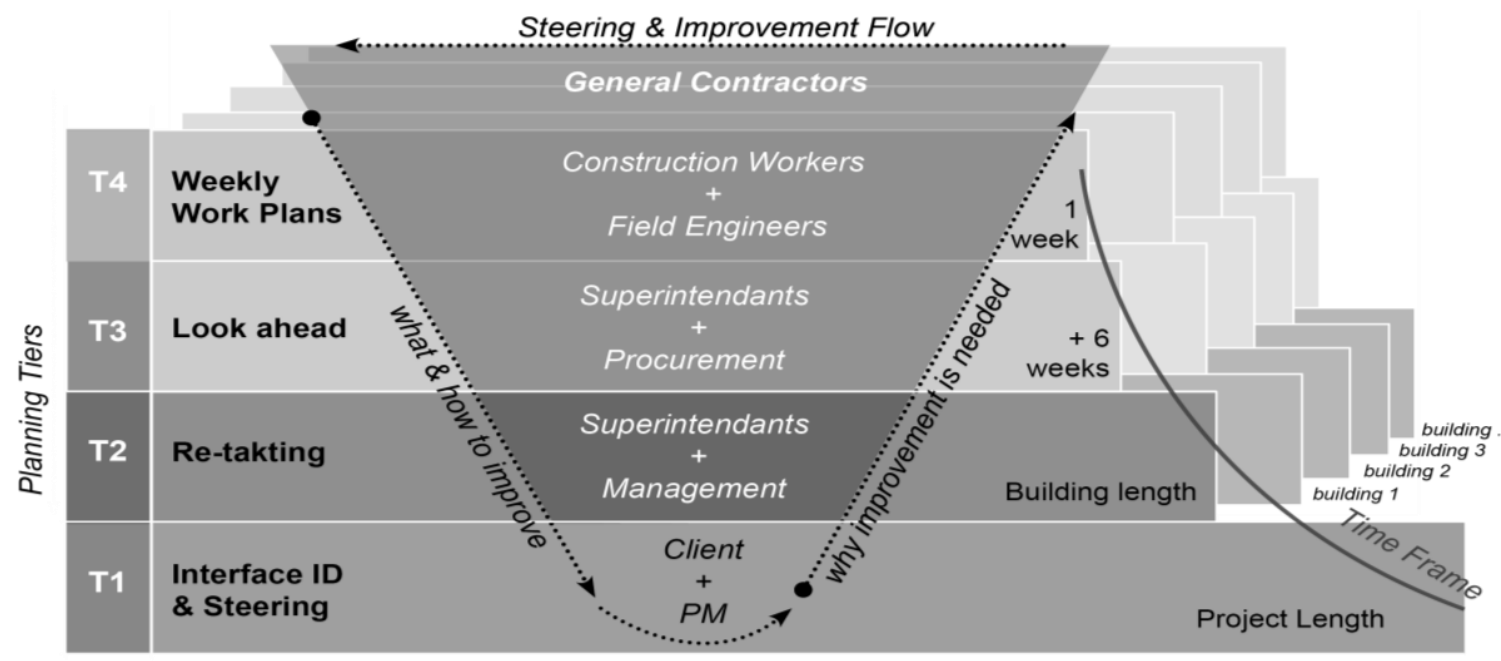

Figure 5: Planning Tier Structure

From a Macro perspective (T1), milestones from different buildings were aligned on a monthly basis. This included main infrastructure and utilities, as well as operational requirements. High reliability Takt schedules, of each building and their required utilities, have proven to be essential to support effective decision making in an ever-changing environment. Each planning tier contributed to sustain the TPTC method.

\section{TRANSPARENT MULTI-LEVEL COMMUNICATION}

Similar to the planning structure, the tools used for multi-level communication were broken down by levels and focused on target groups. Such tools were standardized to maintain transparency between all stakeholders, and focus steering efforts on collective solutions based on trustworthy data. (See figure 6).

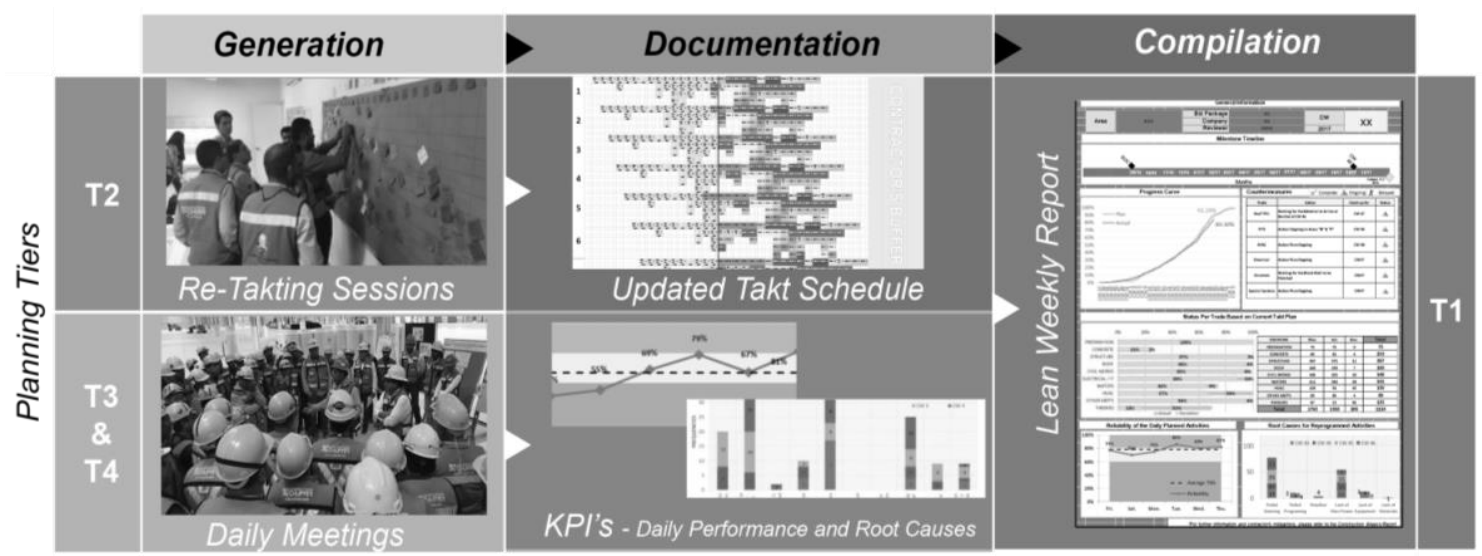

Figure 6: Standard structure and visualization of the construction process.

By standardizing the Takt Schedules (figure 6, upper middle side), the execution of daily meetings and the content for the control boards (figure6, down left side), the building status and progress could be analyzed through the same Key Performance Indicators 
(KPIs) (figure 6, down middle side). Working with the same structure and language to communicate the status of each building allowed a unique Lean Weekly Report (figure 6, right side) to be processed collaboratively by the contractor and client, thus simplifying the visualization of critical interface challenges.

\section{FINDINGS}

\section{PROJECT CONTROL}

A weekly data collection system was implemented, where every Friday contractors' lean responsible updated and uploaded their takt schedules to a document control platform. The information was then reviewed, analysed and validated by the construction management team, creating a database stored in the client's server. At one point there were over 20 different Takt schedules for both, buildings and infrastructure, allowing a comparative analysis between projects behaviour.

This paper focuses the results on the 4 main production buildings: Body Shop, Assembly, Logistics and Laboratory, compiling over 100.000 data points and generating over 1000 Lean Weekly Reports. The data herein shows the project control at 2 different levels: on the Micro the daily performance measured daily and averaged for any given week, and on the Norm progress curves (planned based on Takts complete). Data regarding Root cause frequencies for reprogrammed activities was also gathered but are excluded from this study.

\section{CONTROLLING THROUGH PERFORMANCE AT THE MICRO LEVEL}

Weekly goals were deployed to the micro level as daily quantifiable activities and the performance of the daily plan was recorded. This data was then averaged per week per building. The contractors targeted to achieve a minimum of $80 \%$ reliability every day. Figure 7 shows just under a year of data, gathered for the production buildings. The resulting work averaged $78 \%$ performance, while the target of $80 \%$ was achieved 90 times (or 43\%).

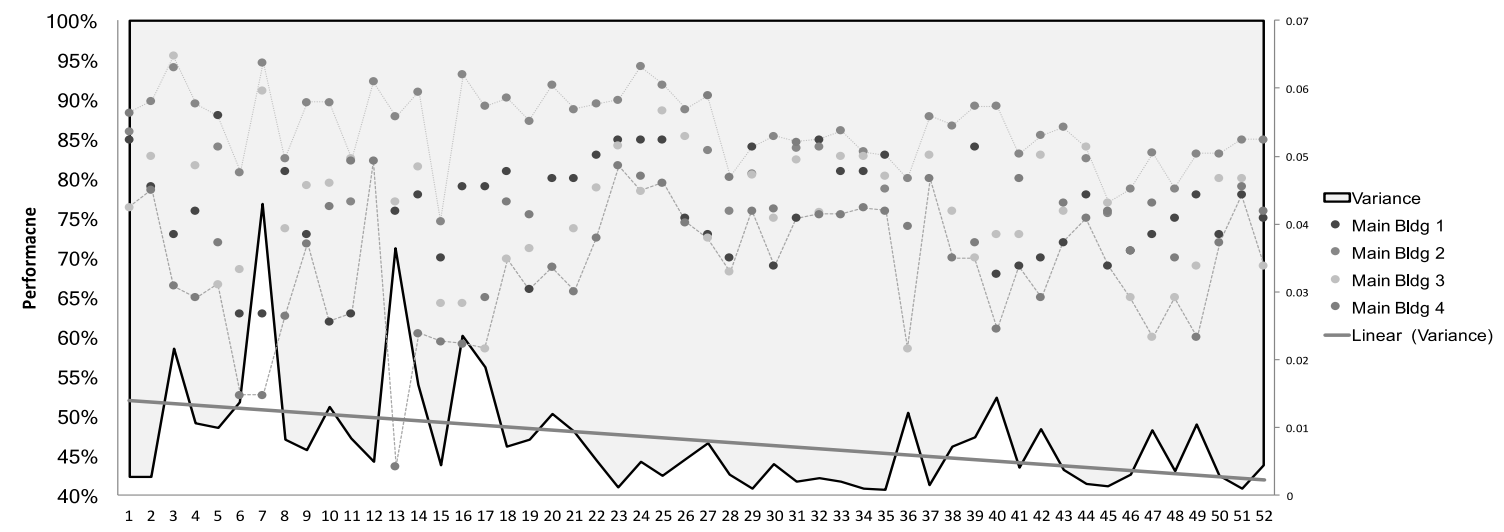

Figure 7: Performance Main Buildings 
As seen in Figure 7, the variance of the performance between each Main Building was significantly reduced over time, accomplishing an overall uniform performance. Less variance in the performance, endoweda higher reliability to daily planned activities, which in turn increased certainty on Takt Schedule sand on Space Provision dates. The reduction of the variance and the increase of reliability on Takt Schedules decreased the complexity of working in a multitasking flow environment as experienced in large-scale projects.

\section{CONTROLLING THROUGH TAKT PLANNING AT THE NORM LEVEL}

From a client's perspective, the result of this project was measured based on achieving 2 main objectives; 1) Gain early access to the main production buildings to allow more time for the installation of assembly line equipment thus overlapping the latter and the remaining construction completion activities, and 2) Achieving the contractual construction finish (space provision).

Through the analysis shown herein, it is possible to observe how building in a Lean environment while using the TPTC method successfully responded to a multitasking flow in a large-scale project, achieving the client's main objectives. The following progress curves (see figure8) show the first and real Takt schedules for the main buildings, including the Space Provision date and the accomplished Early Entries. Note that on average, a construction buffer of 14 weeks was identified for each building through the TPTC method.

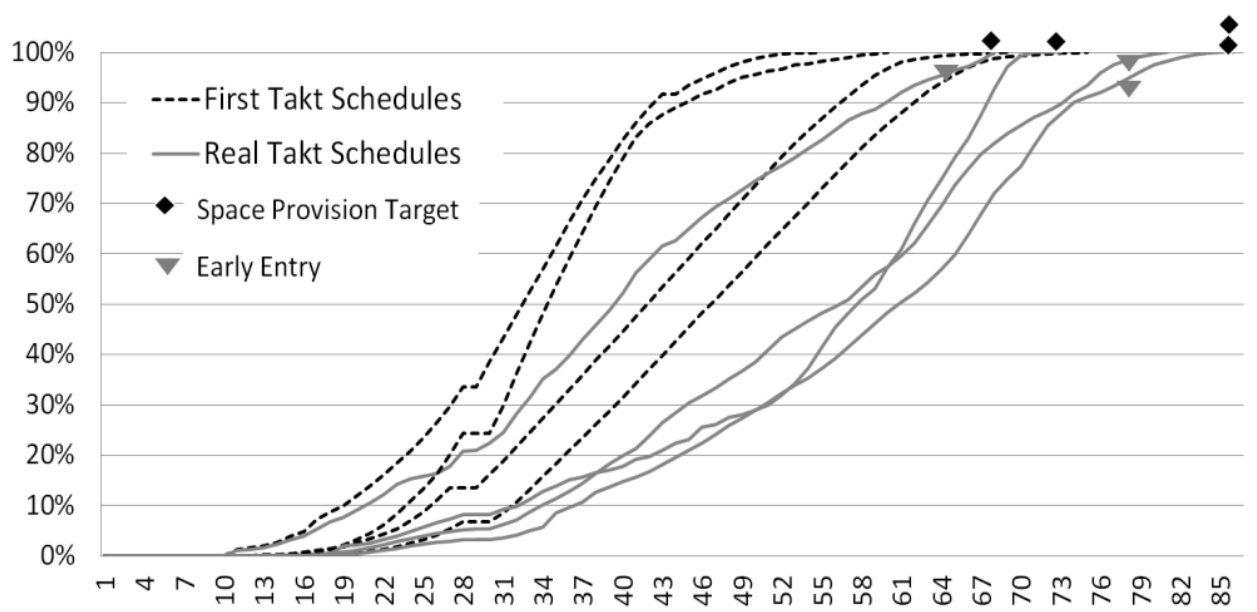

Figure 8: First and Last Takt Sch. With Space Provision and Early Entry Milestones

Maintaining an ideal production plan in construction involves a supply chain that can adapt to the required construction rhythm. Weekly or biweekly reTakting sessions were key to adapt the construction sequence and rhythm, to maintain each project's commitments as response to disruptive elements such as: 1) clients' design improvements during construction 2) the GCs' misalignment of their procurement and design teams and 3) GC's inexperience with the TPTC method. Towards the end of the construction sequence, the buffers were considerably reduced although always fulfilling the Space 
Provision commitments. Figure 9, for example, shows the history of one buildings' Takt schedule continual adaptation of flow to maintain a stable production rhythm.

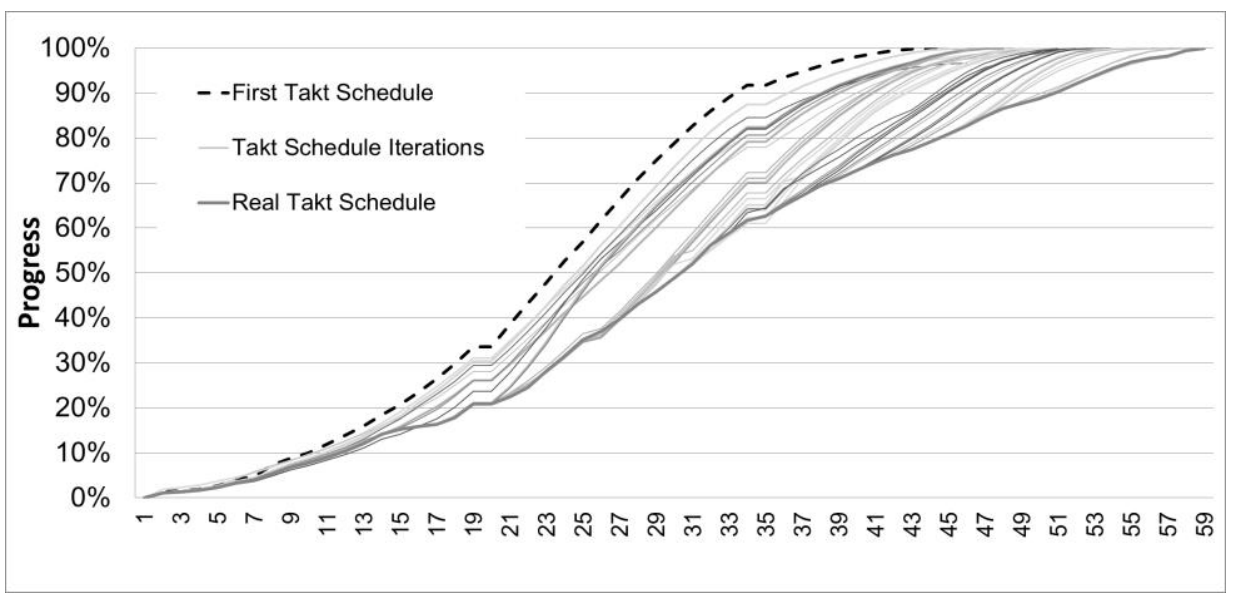

Figure 9: Continual adaptation of the Takt Schedule to maintain flow

\section{CONCLUSIONS AND DISCUSSION}

The system described in this paper implemented in a large scale project, enabled a dynamic and transparent response to changes in priorities, quicker decision making based on performance metrics, and total reporting control in all stages of the construction phase. Furthermore, this system can be used as a platform for TPTC implementation in future projects of similar complexity.

The TPTC method was successfully implemented in Mexico without any previous experience on TPTC by the building teams. This showcases the possibility to implement it in other locations using similar operating systems. Three of the main buildings, studied in this paper, achieved the goal of early entry and the agreed space provision for the fourth.

The overall project transparency, with all single flows created by the large-scale Taktapproach in different construction sites, enabled multitasking adjustments in and at the same time. Quality issues and process instabilities could be detected at a very early stage. For every Takt time, information across the single flows were collected and used for the next Takt times over all projects and general contractors. At the micro-level planning, steering and optimizing flow of trades was possible. At norm-level the flow of the single buildings in Takts was visually made clear and understandable. At the macro-level, for the overall project flow of the whole plant, the customers' needs could be prioritized, maintaining flexibility relying on data and buffer transparency.

To improve future results for large-scale projects, it is necessary to include increased involvement from other project departments (such as design), change management, safety, quality and procurement, as well as integrating a software solution for hosting, processing and analyzing the huge amount of data points generated. Although there was a cultural barrier regarding Lean practices, it was mostly overcome by training, resulting in a 
common use of Lean language and buy-in from both the client and the general contractors.

\section{REFERENCES}

Binninger, M., Dlouhy, J., Haghsheno, S., 2017a. Technical Takt Planning and Takt Control in Construction.,25th Annual Conference of the International Group for Lean Construction. 605-612.

Binninger, M., Dlouhy, J., Oprach, S., Haghsheno, S., 2017b. Learning Simulation Game for Takt Planning and Takt Control, 25th Annual Conference of the International Group for Lean Construction., 227-233.

Dlouhy, J., Binninger, M., Oprach, S., Haghsheno, S., 2016. Three-Level Method of Takt Planning and Takt Control - a New Approach for Designing Production Systems in Construction,Proceedings of the 24th Annual Conference of the International Group for Lean Construction.

Dlouhy, J., Wagner, J., 2018. Lean Construction in Bauherrenorganisationen,Lean Construction - Das Managementhandbuch. Springer Gabler, Berlin, Heidelberg, $105-117$.

Frandson, A., Berghede, K., Tommelein, I.D., 2013. Takt Time Planning for Construction of Exterior Cladding,21th Annual Conference of the International Group for Lean Construction. Presented at the 21th Annual Conference of the International Group for Lean Construction, Fortaleza, Brazil,527-536.

Horman, M.J., Messner, J.I., Riley, D.R., Pulaski, M.H., 2003. Using Buffers to Manage Production: A Case Study of the Pentagon Renovation Project, Proceedings of the 11th Annual Conference of the Internation Group for Lean Construction (IGLC-11), Blacksburg, Virginia. 